\title{
$\mathrm{Fe}-$ 및 $\mathrm{Co}$-질산염을 이용한 $\mathrm{Fe}-50 \mathrm{wt} \% \mathrm{Co}$ 나노분말의 합성 및 특성 평가
}

\author{
류도형 · 오승탁 ${ }^{\dagger}$ \\ 서울과학기술대학교 신소재공학과
}

\section{Fabrication and Characterization of Nano-sized Fe-50 wt\% Co Powder from Fe- and Co-nitrate}

\author{
Doh-Hyung Riu and Sung-Tag $\mathrm{Oh}^{\dagger}$ \\ Department of Materials Science and Engineering, Seoul National University of Science and Technology, \\ Seoul 139-743, Korea
}

(2010년 9월 16일 접수 : 2010년 9월 24일 최종수정 : 2010년 9월 25일 채택)

\begin{abstract}
The optimum route to fabricate nano-sized Fe-50 wt $\%$ Co and hydrogen-reduction behavior of calcined Fe-/Conitrate was investigated. The powder mixture of metal oxides was prepared by solution mixing and calcination of $\mathrm{Fe}-/ \mathrm{Co}$-nitrate. A DTA-TG and microstructural analysis revealed that the nitrates mixture by the calcination at $300^{\circ} \mathrm{C}$ for $2 \mathrm{~h}$ was changed to $\mathrm{Fe}$-oxide/Co3O4 composite powders with an average particle size of $100 \mathrm{~nm}$. The reduction behavior of the calcined powders was analyzed by DTA-TG in a hydrogen atmosphere. The composite powders of Fe-oxide and $\mathrm{Co} 3 \mathrm{O} 4$ changed to a Fe-Co phase with an average particle size of $40 \mathrm{~nm}$ in the temperature range of $260-420^{\circ} \mathrm{C}$. In the TG analysis, a two-step reduction process relating to the presence of $\mathrm{Fe} 3 \mathrm{O} 4$ and a $\mathrm{CoO}$ phase as the intermediate phase was observed. The hydrogen-reduction kinetics of the Fe-oxide/Co3O4 composite powders was evaluated by the amount of peak shift with heating rates in TG. The activation energies for the reduction, estimated by the slope of the Kissinger plot, were $96 \mathrm{~kJ} / \mathrm{mol}$ in the peak temperature range of $231-297^{\circ} \mathrm{C}$ and $83 \mathrm{~kJ} / \mathrm{mol}$ of $290-390^{\circ} \mathrm{C}$, respectively. The reported activation energy of $70.4-94.4 \mathrm{~kJ} / \mathrm{mol}$ for the reduction of $\mathrm{Fe}$ - and Co-oxides is in reasonable agreement with the measured value in this study.
\end{abstract}

Key words Fe-50 wt\% Co powders, synthesis of nano-sized powders, activation energy, microstructure.

\section{1. 서 론}

연자성 재료인 $\mathrm{Fe}-\mathrm{Co}$ 는 상대적으로 낮은 보자력과 높 은 포화자화 값 및 낮은 자기이력 에너지 손실을 나타내 기 때문에 다양한 응용을 위한 활발한 연구가 이루어지 고 있다. ${ }^{1-2)}$ 최근에는 나노구조를 갖는 연자성 재료에 대 한 관심이 증가하고 있는 바, 이는 결정립 크기가 수십 나노미터 이하의 크기로 감소될 때 나타나는 독특한 물 리적 현상에 기인한 연자성 특성의 향상 때문이다. ${ }^{3-4)}$

나노구조를 갖는 분말의 제조방법으로는 기계적합금화법 (mechanical alloying), 화학기상응축법 (chemical vapor condensation) 및 전착 (electrodeposion) 등이 있다. ${ }^{5-6)}$ 기 계적합금화법은 미세한 분말제조와 대량생산을 할 수 있 다는 장점이 있으나 제조과정 중에 혼입되는 불순물의 제 어에 어려움이 있고, 화학기상응축법 및 전착 등은 제조 비용이 비싼 단점 등이 있다. 따라서 최근에는 금속염화

${ }^{\dagger}$ Corresponding author

E-Mail : stoh@snut.ac.kr (S. -T. Oh)
물 이나 금속질화물을 출발원료로 하여 수소환원 공정을 거쳐 나노크기의 분말로 제조하는 화학적 합성법에 관한 연구들이 진행되고 있다.-8) 그러나 요구되는 자성특성을 구현하기 위해서는 입자크기 및 반응상 등의 정밀한 제 어가 필요하며 이는 합성거동에 대한 정량적인 해석과 공 정의 최적화에 관한 연구를 통하여 이루어질 수 있다. 따라서 본 연구에서는 $\mathrm{Fe}-$ 및 $\mathrm{Co}$-질산염을 원료분말로 하여, slurry혼합, 하소 및 수소환원으로 나노크기의 $\mathrm{Fe}-$ $50 \mathrm{wt} \% \mathrm{Co}$ 분말을 합성하고자 하였다. DTA-TG를 이용한 열분석을 통하여 최적의 하소 및 수소환원 온도를 결정 하고 환원거동과 미세조직을 정량적으로 분석하여 최적의 공정조건을 제시하고자 하였다. 또한 다양한 승온속도를 적용한 $\mathrm{TG}$ 분석을 통하여 수소환원 거동을 속도론적 관 점에서 해석하고자 하였다.

\section{2. 실험 방법}

본 연구에서는 $\mathrm{Fe}$-nitrate $\left(\mathrm{Fe}\left(\mathrm{NO}_{3}\right)_{3} \cdot 9 \mathrm{H}_{2} \mathrm{O}\right)$ 와 Co-nitrate 
$\left(\mathrm{Co}\left(\mathrm{NO}_{3}\right)_{2} \cdot 6 \mathrm{H}_{2} \mathrm{O}\right)$ (High Purity Chemetals Lab., Japan)을 원료분말로 사용하였다. 최종조성이 $\mathrm{Fe}-50 \mathrm{wt} \% \mathrm{Co}$ 가 되 도록 금속질산염을 칭량하여 증류수에 충분히 용해한 후 이를 건조하여 혼합도가 높고 미세한 혼합분말로 제조 하였다. 혼합분말의 하소조건을 결정하기 위하여 DTA (differential thermal analysis) - TG (thermogravimetry) 분 석을 실시하였고, 이러한 분석결과를 바탕으로 $300^{\circ} \mathrm{C}$, 대 기 중에서 2시간 동안 하소하였다. 하소한 분말의 수소환 원 거동은 $\mathrm{TG}$ 를 이용하여 수소분위기에서 각각 $1,5,10$, $20^{\circ} \mathrm{C} / \mathrm{min}$ 의 승온속도로 가열하며 중량변화를 측정하여 해 석하였으며, 수소환원의 활성화에너지는 Kissinger방법을 이 용하여 계산하였다. ${ }^{9)}$ 하소 및 수소환원 한 혼합분말의 미 세조직 분석은 $\mathrm{XRD}$ 와 $\mathrm{SEM}$ 및 $\mathrm{TEM}$ 을 이용하여 행하 였다.

\section{3. 결과 및 고찰}

원료분말의 하소조건을 결정하기 위하여 DTA-TG 분석 을 수행하였다. Fig. 1은 Fe-nitrate, Co-nitrate 및 Fe-/Conitrate 혼합분말을 사용하여 대기 중에서 $10^{\circ} \mathrm{C} / \mathrm{min}$ 의 승 온속도로 $700^{\circ} \mathrm{C}$ 까지 가열하여 얻은 결과이다. Fig. 1(a)의 DTA결과에 나타낸 바와 같이, Fe-nitrate는 약 $100^{\circ} \mathrm{C}$ 및 $160^{\circ} \mathrm{C}$ 에서 피크가 관찰되며 Co-nitrate의 경우는 약 $87^{\circ} \mathrm{C}$, $134^{\circ} \mathrm{C}, 196^{\circ} \mathrm{C}$ 및 $243^{\circ} \mathrm{C}$ 에서 피크가 관찰된다. 한편, 혼 합분말의 경우는 순수한 $\mathrm{Fe}-$ 및 $\mathrm{Co}$-nitrate의 피크가 중첩 된 형태로 나타남을 알 수 있다. 이러한 DTA 피크의 변 화는 Fig. 1(b)의 TG 결과와 유사한 경향을 나타내며, 혼 합분말의 경우 $\mathrm{H}_{2} \mathrm{O}$ 의 증발에 따라 약 $50^{\circ} \mathrm{C}$ 부터 시편의 무게가 감소하기 시작하여 $80^{\circ} \mathrm{C}$ 이후로는 급격한 감소가 일어남을 알 수 있다. 최종적으로 온도가 약 $300^{\circ} \mathrm{C}$ 에 이 르면 $53 \%$ 의 무게감소 량으로 거의 일정한 값을 유지하 며 이러한 감소는 주로 질산염의 분해에 기인한 것으로 해석된다.

하소 공정에 따른 상 변화를 확인하기 위하여 하소 전 후의 분말에 대한 XRD 분석을 실시하여 Fig. 2에 나타

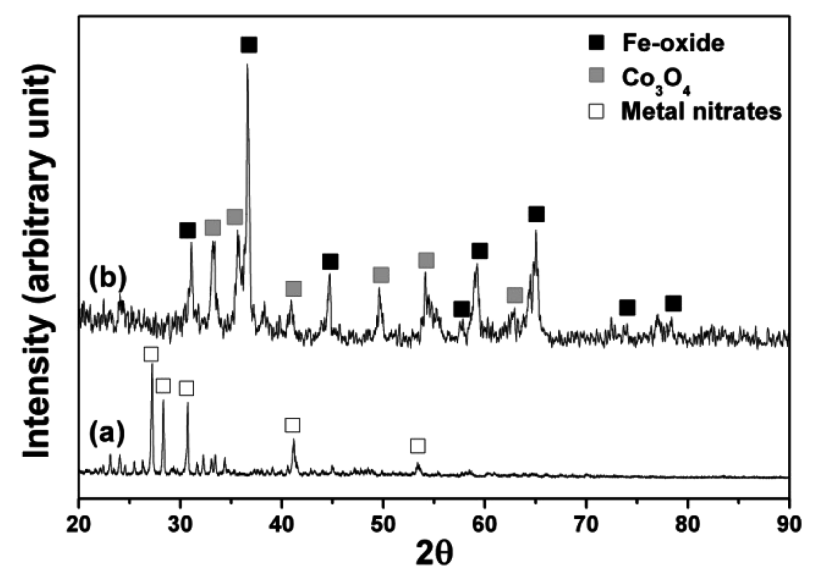

Fig. 2. XRD profiles of (a) before and (b) after calcination of the $\mathrm{Fe}-/ \mathrm{Co}-$ nitrate powders.

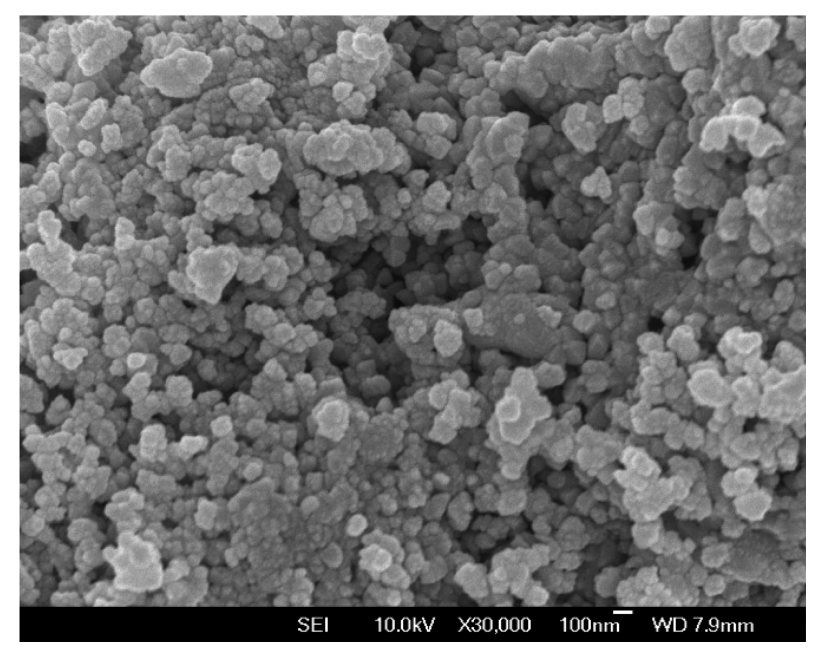

Fig. 3. SEM micrograph of the composite powder, calcined at $300^{\circ} \mathrm{C}$ for $2 \mathrm{~h}$ in air.

내었다. 원료분말은 Fig. 2(a)와 같이 Fe- 및 Co-nitrate상 으로 존재하나 $300^{\circ} \mathrm{C}$ 에서 2시간 동안 하소 후 (Fig. 2b) 에는 금속질산염이 분해되어 $\mathrm{Fe}$-oxide 및 $\mathrm{Co}_{3} \mathrm{O}_{4}$ 상으로만 존재함을 알 수 있다. Fig. 3은 하소한 $\mathrm{Fe}-\mathrm{oxide} / \mathrm{Co}_{3} \mathrm{O}_{4}$ 복 합분말의 SEM 미세조직사진으로서 약 $100 \mathrm{~nm}$ 크기의 입
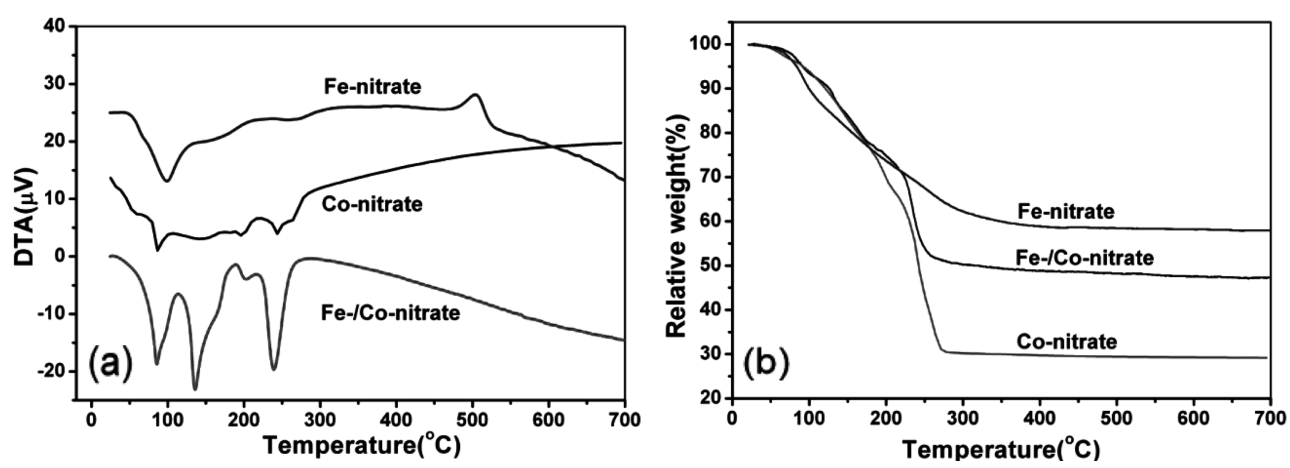

Fig. 1. (a) DTA and (b) TG curves for calcination of Fe-nitrate, Co-nitrate and Fe-/Co-nitrate powders, obtained at a scanning rate of $10^{\circ} \mathrm{C} / \mathrm{min}$. 
자가 응집체를 형성하며 존재함을 알 수 있다.

Fig. 4는 Fe-oxide $/ \mathrm{Co}_{3} \mathrm{O}_{4}$ 복합분말 및 비교를 위하여 $\mathrm{Fe}$-oxide 분말에 대한 수소환원거동을 $\mathrm{TG}$ 를 이용하여 분 석한 결과로, 상대적인 중량변화 곡선과 중량을 온도로 1 차 미분한 곡선을 동시에 나타내었다. Fe-oxide 분말을 승 온속도 $10^{\circ} \mathrm{C} / \mathrm{min}$ 로 수소분위기에서 가열하면 시편내의 잔 류불순물의 증발에 기인하여 점진적인 무게감소가 발생하 다가, 약 $270^{\circ} \mathrm{C}$ 부터는 급격한 무게감소가 일어남을 알 수 있다. 이러한 변화는 1 차 미분곡선에서 뚜렷이 구분할 수 있으며, 특히 $320^{\circ} \mathrm{C}-410^{\circ} \mathrm{C}$ 온도구간에서는 2 개의 무게감 소 피크가 존재함을 알 수 있다.

이러한 2 개의 환원피크가 존재하는 것은 기존에 보고된 연구결과와 잘 일치하는 것으로, ${ }^{10-11)} \mathrm{Fe}-$ oxide의 환원은 아 래 식과 같이 $\mathrm{Fe}_{2} \mathrm{O}_{3}$ 로부터 $\mathrm{Fe}_{3} \mathrm{O}_{4}$ 중간상을 거쳐 최종적 으로 순수한 $\mathrm{Fe}$ 로 단계를 걸쳐 환원되기 때문이다. 한편 $\mathrm{Lin}$ 과 $\mathrm{Chen}$ 은 ${ }^{12)} \mathrm{Co}$-oxide의 수소환원 공정도 $\mathrm{CoO}$ 중간 상을 거쳐 두 단계 $\left(\mathrm{Co}_{3} \mathrm{O}_{4} \rightarrow \mathrm{CoO} \rightarrow \mathrm{Co}\right)$ 로 진행된다고 보고하였다.

$$
\begin{aligned}
& 3 \mathrm{Fe}_{2} \mathrm{O}_{3}+\mathrm{H}_{2} \rightarrow 2 \mathrm{Fe}_{3} \mathrm{O}_{4}+\mathrm{H}_{2} \mathrm{O} \\
& \mathrm{Fe}_{3} \mathrm{O}_{4}+4 \mathrm{H}_{2} \rightarrow 3 \mathrm{Fe}+4 \mathrm{H}_{2} \mathrm{O}
\end{aligned}
$$

Fe-oxide $/ \mathrm{Co}_{3} \mathrm{O}_{4}$ 복합분말은 Fig. 4에서 실선으로 나타낸 바와 같이 상온에서 약 $260^{\circ} \mathrm{C}$ 까지는 점진적으로 무게가 감소하며, $260^{\circ} \mathrm{C}$ 에서 $420^{\circ} \mathrm{C}$ 사이의 온도에서 급격한 무 게 감소가 발생하고 그 이후의 온도에서는 거의 일정한 값을 유지한다. 처음 $260^{\circ} \mathrm{C}$ 까지의 무게감소는 복합분말 내 잔류 불순물의 증발에 의한 것이며 $260^{\circ} \mathrm{C}$ 이상에서의 급 격한 무게감소는 $\mathrm{Fe}$-oxide 및 $\mathrm{Co}_{3} \mathrm{O}_{4}$ 의 수소환원에 의한 $\mathrm{H}_{2} \mathrm{O}$ 증발에 기인한 것으로 해석된다. 한편, 1 차 미분곡 선에서도 2 개의 무게감소 피크가 뚜렷이 관찰되며 이는 각 금속산화물의 단계환원 때문으로 설명할 수 있다. 따 라서 본 실험조건에서 $\mathrm{Fe}-\mathrm{oxide} / \mathrm{Co}_{3} \mathrm{O}_{4}$ 복합분말의 수소환

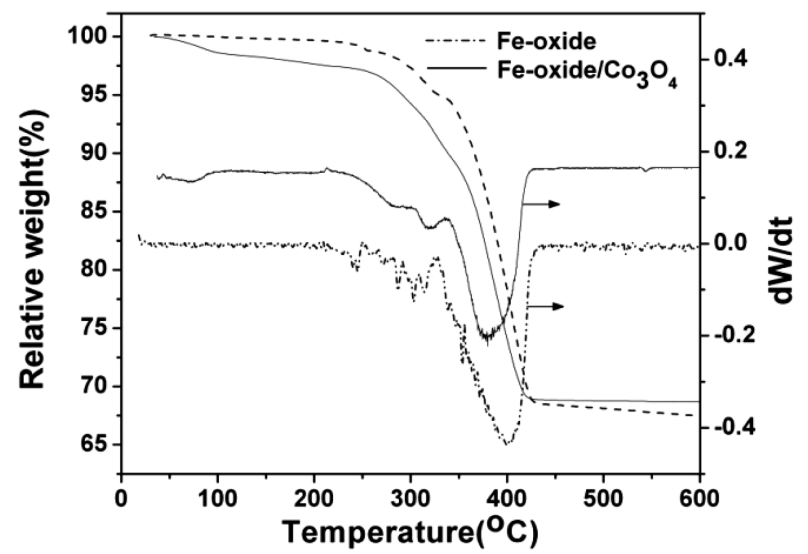

Fig. 4. TG-differential TG curves for hydrogen reduction of the calcined powders, obtained at a scanning rate of $10^{\circ} \mathrm{C} / \mathrm{min}$.

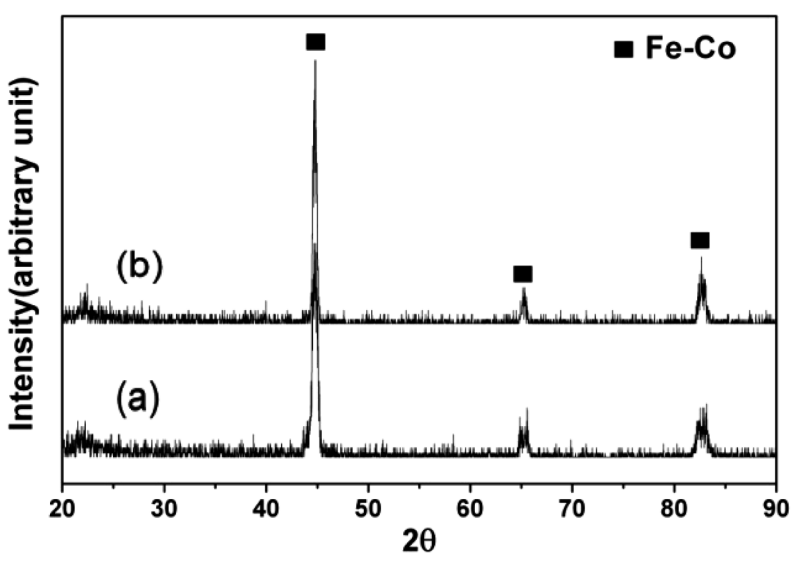

Fig. 5. XRD profiles of the composite powders, hydrogen-reduced at (a) 400 and (b) $600^{\circ} \mathrm{C}$ for $30 \mathrm{~min}$.

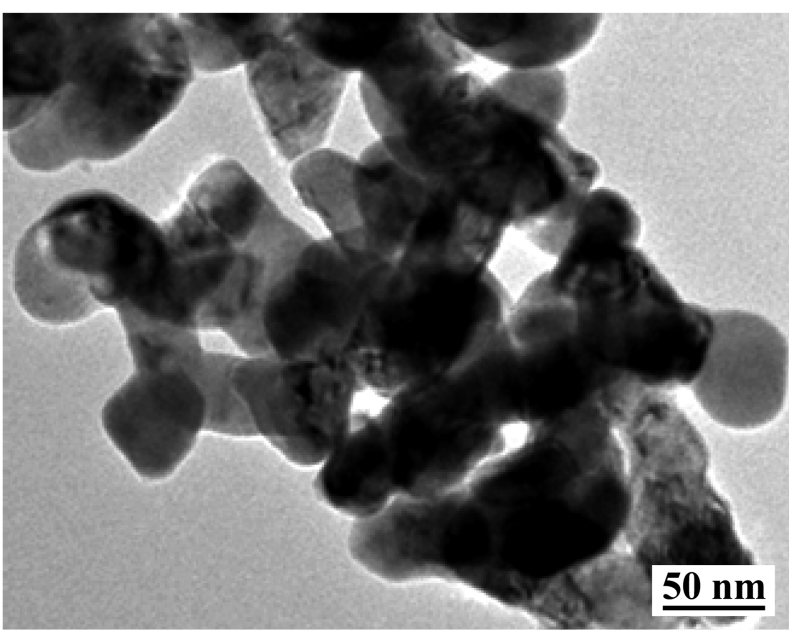

Fig. 6. TEM micrograph of the Fe-Co alloy powder, hydrogenreduced at $400^{\circ} \mathrm{C}$ for $30 \mathrm{~min}$.

원반응 시작온도는 $260^{\circ} \mathrm{C}$ 이며, $420^{\circ} \mathrm{C}$ 에서 금속으로의 환 원반응이 종료된다고 결론지을 수 있다.

수소환원 공정에 따른 상 변화를 확인하기 위하여 $400^{\circ} \mathrm{C}$ 및 $600^{\circ} \mathrm{C}$ 에서 30 분 동안 환원 처리한 $\mathrm{Fe}-$ oxide $/ \mathrm{Co}_{3} \mathrm{O}_{4}$ 복 합분말의 XRD 분석을 행하였다. Fig. 5 는 $400^{\circ} \mathrm{C}$ 에서 환 원한 분말로서 다른 반응상의 형성이 없이 모두 $\mathrm{Fe}-\mathrm{Co}$ 합 금상으로만 이루어져 있음을 나타낸다. 환원온도가 $600^{\circ} \mathrm{C}$ 로 증가하여도 동일한 상으로 존재하며 이러한 합금상은 보고된 $\mathrm{Fe}-\mathrm{Co}$ 상태도에서 나타나는 것과 일치한다. ${ }^{13)} \mathrm{Fig}$. 6 은 $400^{\circ} \mathrm{C}$ 에서 환원한 $\mathrm{Fe}-\mathrm{Co}$ 분말의 $\mathrm{TEM}$ 미세조직사진 으로서 약 $40 \mathrm{~nm}$ 크기의 입자가 응집체를 형성하며 존재 함을 알 수 있다. 따라서, 본 연구결과는 금속질산염의 하 소 및 수소환원 공정을 이용하여 나노크기를 갖는 $\mathrm{Fe}-$ $50 \mathrm{wt} \% \mathrm{Co}$ 분말을 성공적으로 제조할 수 있음을 나타낸다.

$\mathrm{Fe}$-oxide $/ \mathrm{Co}_{3} \mathrm{O}_{4}$ 복합분말의 수소환원 거동을 정량적으 로 해석하기 위하여 승온속도에 따른 $\mathrm{TG}$ 거동을 분석하 였다. Fig. 7은 승온속도에 따른 중량변화를 온도로 1차 
미분한 곡선을 나타낸 것이다. 승온속도의 증가에 따라 최 대 반응속도를 나타내는 온도 $\left(\mathrm{T}_{\mathrm{m}}\right)$ 는 고온으로 이동함을 알 수 있으며, 아래의 Kissinger 식 ${ }^{9)}$ 을 적용하면 이러한 열적 활성화 과정의 변화로부터 활성화 에너지를 계산할 수 있다.

$$
\ln \left(\frac{\Phi}{T_{m}^{2}}\right)=-\frac{Q}{R} \cdot \frac{1}{T_{m}}+\text { const }
$$

여기서 $\Phi$ 는 승온속도, $\mathrm{T}_{\mathrm{m}}$ 은 최대 반응속도의 온도, $\mathrm{R}$ 은 기체상수, $\mathrm{Q}$ 는 활성화 에너지를 나타낸다. 따라서 1/ $\mathrm{T}_{\mathrm{m}}$ 과 $\ln \left(\Phi / \mathrm{T}_{\mathrm{m}}{ }^{2}\right)$ 관계를 plot 하면 기울기로부터 활성화 에 너지 $\mathrm{Q}$ 를 구할 수 있다.

Fig. 7 에서 나타나는 2 개의 최대 반응속도의 온도 $\left(\mathrm{T}_{\mathrm{m} 1}\right.$, $\mathrm{T}_{\mathrm{m} 2}$ )는 $231^{\circ} \mathrm{C}-390^{\circ} \mathrm{C}$ 범위의 값을 가지며 이를 식 (3)에 따라 plot한 결과를 Fig. 8에 나타내었다. $\mathrm{T}_{\mathrm{m} 1}$ 으로 표시한 상대적으로 저온부위의 피크와 $\mathrm{T}_{\mathrm{m} 2}$ 피크에 대한 활성화 에너지는 각각 $96 \mathrm{~kJ} / \mathrm{mol}$ 및 $83 \mathrm{~kJ} / \mathrm{mol}$ 로 계산되었다. $\mathrm{Fe}-$

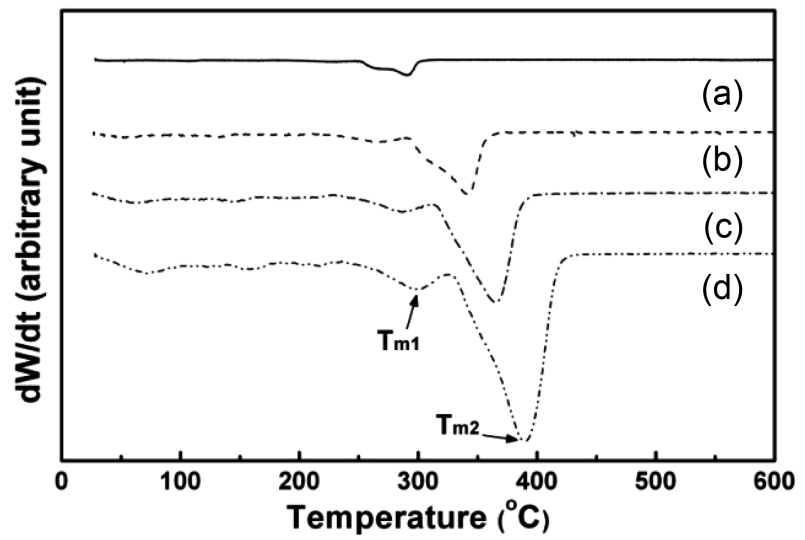

Fig. 7. Differential TG curves of the calcined powders, obtained at heating rates of (a) 1 , (b) 5 , (c) 10 and (d) $20^{\circ} \mathrm{C} / \mathrm{min}$ in a hydrogen atmosphere.

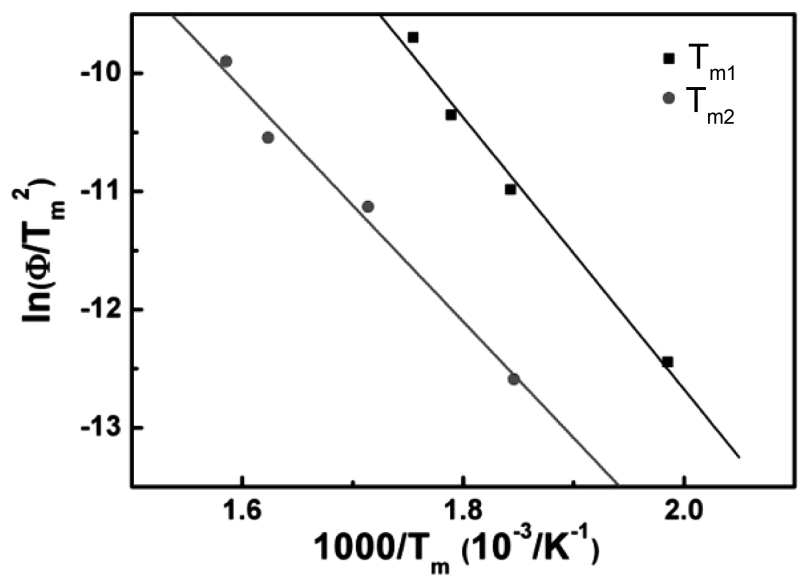

Fig. 8. Activation energies for the hydrogen reduction of Fe-oxide/ $\mathrm{Co}_{3} \mathrm{O}_{4}$ powders.
Table 1. Apparent activation energy of the metal oxides reduction by hydrogen.

\begin{tabular}{cccc}
\hline Reduction step & $\begin{array}{c}\text { Temperature } \\
\text { range }\left({ }^{\circ} \mathrm{C}\right)\end{array}$ & $\begin{array}{c}\text { Activation } \\
\text { energy }(\mathrm{kJ} / \mathrm{mol})\end{array}$ & Ref. \\
\hline $\mathrm{Fe}_{2} \mathrm{O}_{3} \rightarrow \mathrm{Fe}_{3} \mathrm{O}_{4}$ & $300-900$ & 89.1 & $(10)$ \\
$\mathrm{Fe}_{2} \mathrm{O}_{3} \rightarrow \mathrm{Fe}_{3} \mathrm{O}_{4}$ & $220-683$ & 75.9 & $(11)$ \\
$\mathrm{Fe}_{3} \mathrm{O}_{4} \rightarrow \mathrm{Fe}$ & $300-900$ & 70.4 & $(10)$ \\
$\mathrm{Fe}_{3} \mathrm{O}_{4} \rightarrow \mathrm{Fe}$ & $220-450$ & 88.0 & $(11)$ \\
$\mathrm{Co}_{3} \mathrm{O}_{4} \rightarrow \mathrm{CoO}$ & $150-550$ & 94.4 & $(12)$ \\
$\mathrm{CoO} \rightarrow \mathrm{Co}$ & $150-550$ & 83.0 & $(12)$ \\
\hline
\end{tabular}

oxide $/ \mathrm{Co}_{3} \mathrm{O}_{4}$ 복합분말의 수소환원에 대한 활성화 에너지는 보고되어 있지 않아 직접적인 비교가 불가능하나, Table 1 과 같이 $\mathrm{Fe}_{2} \mathrm{O}_{3}, \mathrm{Fe}_{3} \mathrm{O}_{4}, \mathrm{Co}_{3} \mathrm{O}_{4}$ 및 $\mathrm{CoO}$ 의 수소환원에 따른 활성화 에너지는 $70.4-94.4 \mathrm{~kJ} / \mathrm{mol}$ 의 값을 나타낸다. ${ }^{10-12,14)}$ $\mathrm{Lin}$ 등의 연구결과에 의하면 $\mathrm{Fe}_{2} \mathrm{O}_{3}$ 및 $\mathrm{Fe}_{3} \mathrm{O}_{4}$ 의 최대 환 원반응 온도는 각각 $326^{\circ} \mathrm{C}$ 및 $450^{\circ} \mathrm{C}$ 이며, $\mathrm{Co}_{3} \mathrm{O}_{4}$ 및 $\mathrm{CoO}$ 의 온도는 각각 $299^{\circ} \mathrm{C}$ 및 $366^{\circ} \mathrm{C}$ 이다. 따라서 본 연구에 서 계산한 활성화 에너지 값은 기존에 보고된 $\mathrm{Fe}-$ 및 $\mathrm{Co}-$ 산화물의 수소환원에 관한 값과 유사한 경향을 보이고 있 으나, 명확한 환원거동의 설명을 위해서는 단계별 반응의 환원기구 및 복합분말에서의 환원기구에 대한 후속연구가 요구된다.

\section{4. 결}

본 연구에서는 $\mathrm{Fe}$ - 및 $\mathrm{Co}$-질산염 원료분말의 하소 및 수소환원 공정으로 나노크기의 $\mathrm{Fe}-50 \mathrm{wt} \% \mathrm{Co}$ 분말을 합성 하기 위한 최적의 공정조건을 제시하고 수소환원 거동을 정량적으로 해석하고자 하였다. DTA-TG 분석을 통하여 하 소조건을 결정하였으며, 원료분말은 $300^{\circ} \mathrm{C}$ 에서 2 시간 동안 의 하소처리로 약 $100 \mathrm{~nm}$ 크기의 $\mathrm{Fe}-0 x i d e / \mathrm{Co}_{3} \mathrm{O}_{4}$ 복합분말 로 제조할 수 있었다. 수소분위기에서의 $\mathrm{TG}$ 분석으로 복합 분말은 약 $260^{\circ} \mathrm{C}$ 에서 $420^{\circ} \mathrm{C}$ 사이에서 환원이 일어나며, 환원 중 중간상의 형성 때문에 2 단계의 과정을 거쳐 최 종적으로 금속으로 변환됨을 확인하였다. $400^{\circ} \mathrm{C}$ 에서 30 분 동안 환원 처리한 $\mathrm{Fe}-$ oxide $/ \mathrm{Co}_{3} \mathrm{O}_{4}$ 복합분말은 $\mathrm{Fe}-\mathrm{Co}$ 합금 상으로만 존재하며 평균입자크기는 $40 \mathrm{~nm}$ 를 나타내었다. 하소한 복합분말의 수소환원 거동은 승온속도에 따른 TG 거동을 분석하여 평가하였다. Kissinger 식으로 계산한 수 소환원 반응의 활성화 에너지는 $96 \mathrm{~kJ} / \mathrm{mol}$ 및 $83 \mathrm{~kJ} / \mathrm{mol}$ 이 며, 이는 기존에 보고된 $\mathrm{Fe}-$ 및 $\mathrm{Co}$-산화물의 수소환원에 관한 값과 유사한 경향을 나타내었다.

\section{참 고 문 헌}

1. M. E. McHenry, M. A. Willard and D .E. Laughlin, Progr. 
Mater. Sci., 44, 291 (1999).

2. T. Sourmail, Progr. Mater. Sci., 50, 816 (2005).

3. H. Gleiter, Nanostruct. Mater., 1(1), 1 (1992).

4. Y. Nie, H. H. He, R. Z. Gong and X. C. Zhang, J. Magn. Magn. Mater., 310(1), 13 (2007).

5. C. Kuhrt and L. Schultz, J. Appl. Phys. 73(1993) 658890.

6. B. K. Kim, Z. H. Wang, C. J. Choi, Z. D. Zhang and J. C. Kim, J. Kor. Powd. Metal. Inst. (in Korean), 9(5), 322 (2002).

7. B. -H. Lee, Y. J. Lee, K. H. Min, D. -G. Kim and Y. D. Kim, Mater. Lett., 59(24-25), 3156 (2005).

8. S. -T. Oh, M. -H. Joo, Y. -H. Choa, K. H. Kim and S.
-K. Lee, Phys. Scripta, T139, 014050 (2010).

9. H. E. Kissinger, Anal. Chem., 29(11), 1702 (1957).

10. H. -Y. Lin, Y. -W. Chen and C. Li, Thermochim. Acta, 400(1-2), 61 (2003).

11. A. Pineau, N. Kanari and I. Gaballah, Thermochim. Acta, 447(1), 89 (2006).

12. H. -Y. Lin and Y. -W. Chen, Mater. Chem. Phys., 85(1), 171 (2004).

13. I. Ohnuma, H. Enokia, O. Ikeda, R. Kainuma, H. Ohtani, B. Sundman and K. Ishida, Acta Mater., 50(2), 379 (2002).

14. M. V. C. Sastri, R. P. Viswanath, B. Viswanathan, Int. J. Hydrogen Energ., 7(12), 951 (1982). 